\title{
ADAMTS9 is Silenced by Epigenetic Disruption in Colorectal Cancer and Inhibits Cell Growth and Metastasis by Regulating Akt/p53 Signaling
}

\author{
Ling Chen Jun Tang Yixiao Feng Shuman Li Qin Xiang Xiaogian He \\ Guosheng Ren Weiyan Peng Tingxiu Xiang \\ Chongqing Key Laboratory of Molecular Oncology and Epigenetics, the First Affiliated Hospital of \\ Chongqing Medical University, Chongqing, China
}

\section{Key Words}

ADAMTS9 • Colorectal cancer • Tumor suppressor • Methylation

\begin{abstract}
Background/Aims: ADAMTS (disintegrin-like and metalloproteinase with thrombospondin motifs) proteins are extracellular zinc metalloproteinases that play an important role in extracellular matrix assembly and degradation, connective tissue structuring, angiogenesis, and cell migration. Multiple studies suggest that ADAMTS proteins (e.g. ADAMTS9) can act as tumor suppressors. In gastric, esophageal, and nasopharyngeal carcinomas ADAMTS9 is frequently down-regulated by promoter methylation. Whether ADAMTS9 can function as a tumor suppressor gene (TSG) in colorectal cancer is still unclear. Methods: We performed immunohistochemistry, RT-PCR, and qRT-PCR, to examine the expression of ADAMTS9 in colorectal cancer cell lines and primary colorectal cancer tissues. Methylation-specific PCR was also carried out to investigate the promoter methylation status of ADAMTS9. We also explored the functions of ADAMTS9 in colorectal cancer cell lines through in vitro experiments. Results: ADAMTS9 expression was down-regulated or silenced in $83.3 \%(5 / 6)$ of colorectal cancer cell lines, and frequently repressed in $65.6 \%$ (21/32) of colorectal cancer tissues. Downregulation of ADAMTS9 was partially due to promoter methylation. Exogenous expression of ADAMTS9 in colorectal cancer cell lines inhibited cell proliferation and migration through the regulation of cell cycle and apoptosis. In addition, ADAMTS9 prevented the activation of Akt, and its downstream targets in colorectal cancer cell lines. Conclusion: Our findings suggest ADAMTS9 is a TSG in colorectal cancer.
\end{abstract}

\section{KARGER}




\section{Cellular Physiology Cell Physiol Biochem 2017;44:1370-1380

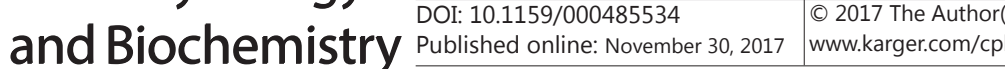 \\ Chen et al.: ADAMTS9 As Tumor Suppressor in Colorectal Cancer}

\section{Introduction}

Colorectal cancer (CRC) has caused high morbidity and mortality worldwide. According to global cancer statistics, in 2012 CRC accounted for $10 \%$ and $9.21 \%$ of all new cancer cases in men and women, respectively; and for $8.02 \%$ and $9.03 \%$ of deaths by cancer in men and women, respectively [1].

CRC progresses through a series of histopathologic stages: atrophy, metaplasia, dysplasia and carcinoma [2-3]. This progression is the result of a series of multiple genetic and epigenetic changes [4-5].

DNA CpG (CG dinucleotide) methylation, an important form of epigenetic modification, often results in the hypermethylation of specific gene promoters and the inactivation of tumor suppressor genes (TSGs) [6-7]. Silencing of TSGs by epigenetic modification is a fundamental contribution to tumor development [8].

ADAMTS (disintegrin-like and metalloproteinase with thrombospondin motifs) is an important family of zinc-dependent proteases, which in humans contains 19 members. ADAMTS proteins play a significant role in various physiological and pathological processes, including wound healing, angiogenesis, cancer, atherosclerosis, arthritis, blood coagulation, melanoblast development, extracellular matrix turnover, and inter-digital web regression [9-10].

ADAMTS9, which encodes a member of the ADAMTS family [11], is located on chromosome 3p14.2-14.3. This chromosome region is lost in multiple tumors, including hereditary renal tumors, cervical cancer and nasopharyngeal carcinoma [11-13]. It has been suggested that ADAMTS9 is silenced by promoter methylation, and that it is associated with tumor suppression in gastric cancer, in esophageal squamous cell carcinoma, in nasopharyngeal carcinoma and in multiple myeloma [14-17].

Here, we evaluated the frequency of ADAMTS9 inactivation in colorectal cancer and explored its functions and mechanisms in CRC cell lines.

\section{Materials and Methods}

\section{Cell culture and human tissue specimens}

Colorectal cancer cell lines HCT15, SW480, LoVo, and CaCo2 were purchased from ATCC. HCT116 and HT29 were kindly provided by Prof. Qian Tao (the Chinese University of Hongkong, China). Cells were maintained at $37{ }^{\circ} \mathrm{C}$, in a humidified atmosphere containing $5 \% \mathrm{CO}_{2}$, in RPMI 1640 (Gibco-BRL, USA) medium supplemented with $10 \%$ fetal bovine serum (Gibco, USA), $100 \mathrm{U} / \mathrm{ml}$ of penicillin, and $100 \mathrm{mg}$ / $\mathrm{ml}$ streptomycin [18]. For DNA demethylation, cells were treated with $10 \mu \mathrm{M}$ 5-aza-2'-deoxycytidine (Aza; Sigma-Aldrich) for 3 days and then treated with $100 \mathrm{nM}$ histone deacetylase inhibitor trichostatin A (TSA; Cayman Chemical Co.) for 1 day. Primary colorectal cancer tissues and paired cancer adjacent normal tissues were obtained from the Surgery Department of the First Affiliated Hospital of Chongqing Medical University (Chongqing, China).

\section{Immunohistochemistry (IHC) analysis}

Twenty-three primary colon carcinoma tissues and 20 corresponding tumor adjacent tissues were used to evaluate ADAMTS9 protein expression and location by IHC staining. Anti-ADAMTS 9 antibody was from Santa Cruz (1:50, sc-21502; Santa Cruz Biotechnology, California). IHC was performed as described previously [19]. Images were captured with a Leica microscope photography system and the mean optical density was analyzed using Image Pro Plus 6.0 (Silver Spring, MD, USA).

\section{Methylation-specific PCR (MSP)}

Genomic DNA was extracted from cells and tissue specimens using the QIAamp DNA Mini Kit (Qiagen, Hilden, Germany). Bisulfite modified DNA was amplified by MSP using methylation-specific primer pairs as described previously [20-21]. The primer sequences for methylated ADAMTS9 promoter are 5'-TTTTTCGTTTTTTTTTGTTCGTTC-3' and 5'-AAACTAAACCG CTCGAACCG-3'; primer sequences for the un- 


\section{Cellular Physiology Cell Physiol Biochem 2017;44:1370-1380

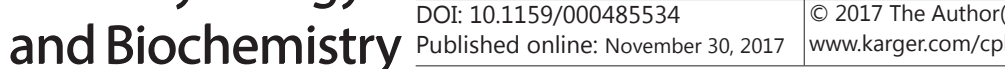 \\ Chen et al.: ADAMTS9 As Tumor Suppressor in Colorectal Cancer}

methylated promoter are 5'-GTTTTTTGTT TTTTTTTGTTTGTTT -3' and 5' - AAAAACTAAACCAC TCAAACCA -3'. MSP was performed for 40 cycles with an annealing temperature of either $60^{\circ} \mathrm{C}$ or $58^{\circ} \mathrm{C}$ using AmpliTaqGold DNA Polymerase (Applied Biosystems, Foster City, CA, USA).

\section{Generation of cell lines with stable overexpression of ADAMTS9}

The plasmids pCEP4 (+)-ADAMTS9 or pCEP4 (+) were transfected into CaCo2 and HCT116 cells using Lipofectamine 2000 reagent according to the manufacturer's protocols (Invitrogen, USA). Forty-eight hours post-transfection, CaCo2 and HCT116 cells were selected for 2-4 weeks with hygromycin (Sigma) at a concentration of $300 \mu \mathrm{g} / \mathrm{ml}$ and $200 \mu \mathrm{g} / \mathrm{ml}$, respectively. Total RNA and protein from the transfected cells were extracted, and analyzed by RT-PCR, or western blot, to confirm the expression of ADAMTS9 in stable cells.

\section{Semiquantitative RT-PCR and quantitative RT-PCR}

Total RNA was extracted from cells and tissues using Trizol reagent (Invitrogen, USA), according to the manufacturer's instructions. RT-PCR was performed as described previously [22]. PCR components were added to a $10-\mu \mathrm{l}$ reaction mixture that included $2 \mu \mathrm{l}$ of cDNA. GAPDH was used as a control to assess the overall cDNA content. The primer sequences for ADAMTS9 are 5'-CATGCAGTT TGTATCCTG-3', and 5'-GCGTTCTTTTGAAGTGGACG-3'. RT-PCR was performed for 32 cycles for ADAMTS9 and 23 cycles for GAPDH using Go-Taq (Promega, Madison, WI, USA). Agarose gel electrophoresis (120 V, 25 min) was performed on a $\%$ agarose gel. Results were analyzed using a BioRad's Gel Doc XR+ system (Bio-Rad, USA).

Quantitative RT-PCR was performed using Maxima SYBR Green/ROX qPCR Master Mix (MBI Fermentas, St. Leon-Rot, Germany) on an ABI 7500 Real-Time PCR System (Applied Biosystems). The expression levels of ADAMTS9 in normal colorectal tissues were set as baseline levels.

\section{Colony formation assay}

CaCo2 and HCT116 cells were collected, and then plated in six-well plates in triplicate. Forty-eight hours post-transfection, the transfectants were selected for 2-3 weeks with hygromycin (Sigma) at a concentration of $300 \mu \mathrm{g} / \mathrm{ml}$ (CaCo2 cells) or $200 \mu \mathrm{g} / \mathrm{ml}$ (HCT116 cells), as previously described [23]. Surviving colonies were stained with gentian violet after methanol fixation, and visible colonies ( $\geq 50$ cells/ colony) were counted.

\section{Cell proliferation assay}

Forty-eight hours after transient transfection with pCEP4 (+)-ADAMTS9 or pCEP4 (+) plasmids (4 $\mu \mathrm{g}$ each), CaCo2 and HCT116 cells were transferred to 96 -well plates $\left(2 \times 10^{3}\right.$ cells per well, in triplicate). Proliferation was measured using the Cell Counting Kit-8 (CCK-8, Beyotime, Shanghai, China) after 0 h, 24 h, $48 \mathrm{~h}$, and $72 \mathrm{~h}[24]$.

\section{Cell cycle and apoptosis analysis}

For cell cycle analysis, CaCo2 and HCT116 cells were cultured overnight in six-well plates at 70-80\% density. Cells were then transfected with $4 \mu \mathrm{g}$ pCEP4 (+)-ADAMTS9 plasmid or the control vector using Lipofectamine-2000, according to the manufacturer's instructions. Forty-eight hours after transfection, cells were harvested and centrifuged at $200 \times \mathrm{g}$ for $5 \mathrm{~min}$. Cells were then washed with PBS twice and fixed overnight in $70 \%$ ice-cold ethanol. Fixed cells were then treated with $50 \mu \mathrm{g} / \mathrm{ml} \mathrm{RNase}$ at $37^{\circ} \mathrm{C}$ for $30 \mathrm{~min}$, and stained with $50 \mu \mathrm{g} / \mathrm{ml}$ propidium iodide for $30 \mathrm{~min}$ at room temperature, in the dark. Data were analyzed by flow cytometry, using a FACSCalibur instrument and the CELL-QUEST software (Becton Dickinson).

Apoptosis assays were performed using the FITC Annexin V Apoptosis Detection Kit I (BD Biosciences) by flow cytometry. CaCo2 and HCT116 cells, transfected with either the pCEP4 (+)-ADAMTS9 plasmid or the control vector, were harvested $48 \mathrm{~h}$ after transfection. Apoptosis and cell viability were measured by FITCAnnexin V and propidium iodide (PI) staining. Cell populations were categorized as viable (Annexin V-, PI-), early apoptotic (Annexin V+, PI-), or late apoptotic cells (Annexin V+, PI+). Both late and early apoptotic cells were counted together for relative apoptotic changes. All experiments were performed three times.

\section{Cell migration assay}

Migration assays were performed using transwell inserts (Corning, NY, USA) containing an 8- $\mu \mathrm{m}$ poresize PET membrane. Cells were trypsinized and resuspended in serum-free RPMI 1640 medium at a density of $10 \times 10^{5}$ cells $/ \mathrm{ml}$. RPMI 1640 medium $(700 \mu \mathrm{l})$ containing $10 \%$ fetal bovine serum was placed in the KARGER 


\section{Cellular Physiology Cell Physiol Biochem 2017;44:1370-1380 \begin{tabular}{ll|l} 
and Biochemistry 10.1159/000485534 & $\begin{array}{l}\text { O) 2017 The Author(s). Published by S. Karger AG, Basel } \\
\text { www.karger.com/cpb }\end{array}$
\end{tabular} \\ Chen et al.: ADAMTS9 As Tumor Suppressor in Colorectal Cancer}

lower chamber of the transwells, and $100 \mu \mathrm{l}$ of the cell suspension was added into the upper chamber. After incubation at $37{ }^{\circ} \mathrm{C}$ for $36 \mathrm{~h}$ (CaCo2 cells) or $48 \mathrm{~h}$ (HCT116 cells), cells on the upper side were removed carefully with cotton swabs, and cells that migrated to the lower chamber were fixed with methanol, stained with $0.05 \%$ crystal violet, and counted under a light microscope. The experiment was performed three times.

\section{Western blot analysis}

Transfected cells were lysed in M-PERM Mammalian Protein Extraction Reagent (Pierce, Thermo Scientific, UK) containing a protease inhibitor cocktail (Sigma Aldrich) and PMSF. Lysates containing $40 \mu \mathrm{g}$ protein were separated by sodium dodecyl sulfate/polyacrylamide gel electrophoresis and then transferred to PVDF membranes (Bio-Rad, Hercules, CA, USA). After blocking with $5 \%$ non-fat milk and $0.1 \%$ Tween 20 in TBS, membranes were incubated with the following primary antibodies: ADAMTS9 (sc-21500), MDM2 (sc-965), p53 (sc-126), and vimentin (sc-6260) from Santa Cruz Biotechnology; p21 (\#2947), p27 (\#3686), caspase 9 (\#9502), cleaved caspase 9 (\#9501), caspase 3 (\#9662), cleaved caspase 3 (\#9664), Akt (\#4691), phospho-Akt (\#4060), GAPDH (\#2118), anti-rabbit IgG, and anti-mouse IgG HRP from Cell Signaling Technology; E-cadherin (ab40772) and $\beta$-actin (ab9485) from Abcam; VEGFA (TA500042, Origene) and anti-goat IgG HRP from Liankebio (RAG007). Immunoblots were visualized using an enhanced chemiluminescence detection system (Pierce Chemical Co., Rockford, IL, USA) and blots were developed using a Fujifilm Las-4000 Imaging System.

\section{Statistical analysis}

Statistical analysis was performed using the SPSS software (SPSS Inc., Chicago, IL). The expression of ADAMTS9 in tumor tissues, and its expression in the corresponding normal adjacent tissues, were compared using Student's t-tests. RT-PCR data were analyzed using the $2^{-\Delta \Delta C t}$ method, using GAPDH as a reference gene. Data on colony formation, cell proliferation and cell migration are expressed as mean \pm SD from three independent experiments. Statistical significance was analyzed by $\mathrm{x}^{2}$-tests or 2 -tailed t-tests. Fisher's exact test was used when appropriate. Differences were considered statistically significant if the $\mathrm{p}$ value was less than 0.05 .

\section{Results}

ADAMTS9 is down-regulated in CRC cell lines and in primary colorectal tumors

Expression of ADAMTS 9 at the protein level was detected by IHC in 23 primary tumors and 20 of the corresponding tumor adjacent normal tissues. IPP 6.0 analysis showed that ADAMTS9 protein level was lower in colon tumor tissues than that in tumor adjacent normal tissues (Fig. 1A, $p<0.05$ ). ADAMTS9 expression location is in agreement with these data from the human proteinatlas (http://www.proteinatlas.org/) (Fig. 1B).

Relative to normal tissue, the expression of ADAMTS9 mRNA was down-regulated in $65.6 \%(21 / 32)$ of colorectal cancer tissues ( $\mathrm{p}<0.05$, Fig. 1C). However, lower expression of ADAMTS9 in CRC did not correlate with its differentiation and histological classification (data not shown)-According to RT-PCR analysis, ADAMTS9 expression was absent in 3 of the 6 colorectal cell lines tested, and weakly expressed in HCT15 and HT29 cell lines (Fig. 1D).

\section{Promoter methylation contributes to ADAMTS9 down-regulation in CRC}

We sought to determine whether promoter methylation is involved in ADAMTS9 downregulation in colorectal cancer. Typical $\mathrm{CpG}$ islands were found in the promoter region of ADAMTS9 using CpG island analysis software (http://cpgislands.usc.edu) (data not shown). MSP was used to analyze the ADAMTS9 promoter methylation status in CRC. Methylation of the ADAMTS9 promoter was observed in all CRC cell lines, which was consistent with its low expression or absence (Fig. 1D).

To determine whether ADAMTS9 silencing was a direct result of promoter methylation, we treated HCT116 and CaCo2 cells with Aza and TSA, and then performed MSP analysis. After the demethylation treatment, we observed decreased methylation of the ADAMTS9 promoter, and restored ADAMTS9 expression (Fig. 1E). 


\section{Cellular Physiology Cell Physiol Biochem 2017;44:1370-1380 \begin{tabular}{l|l|l}
\cline { 2 - 3 } DOI: 10.1159/000485534 & (c) 2017 The Author(s). Published by S. Karger AG, Basel
\end{tabular} and Biochemistry Published online: November 30, 2017 www.karger.com/cpb}

A

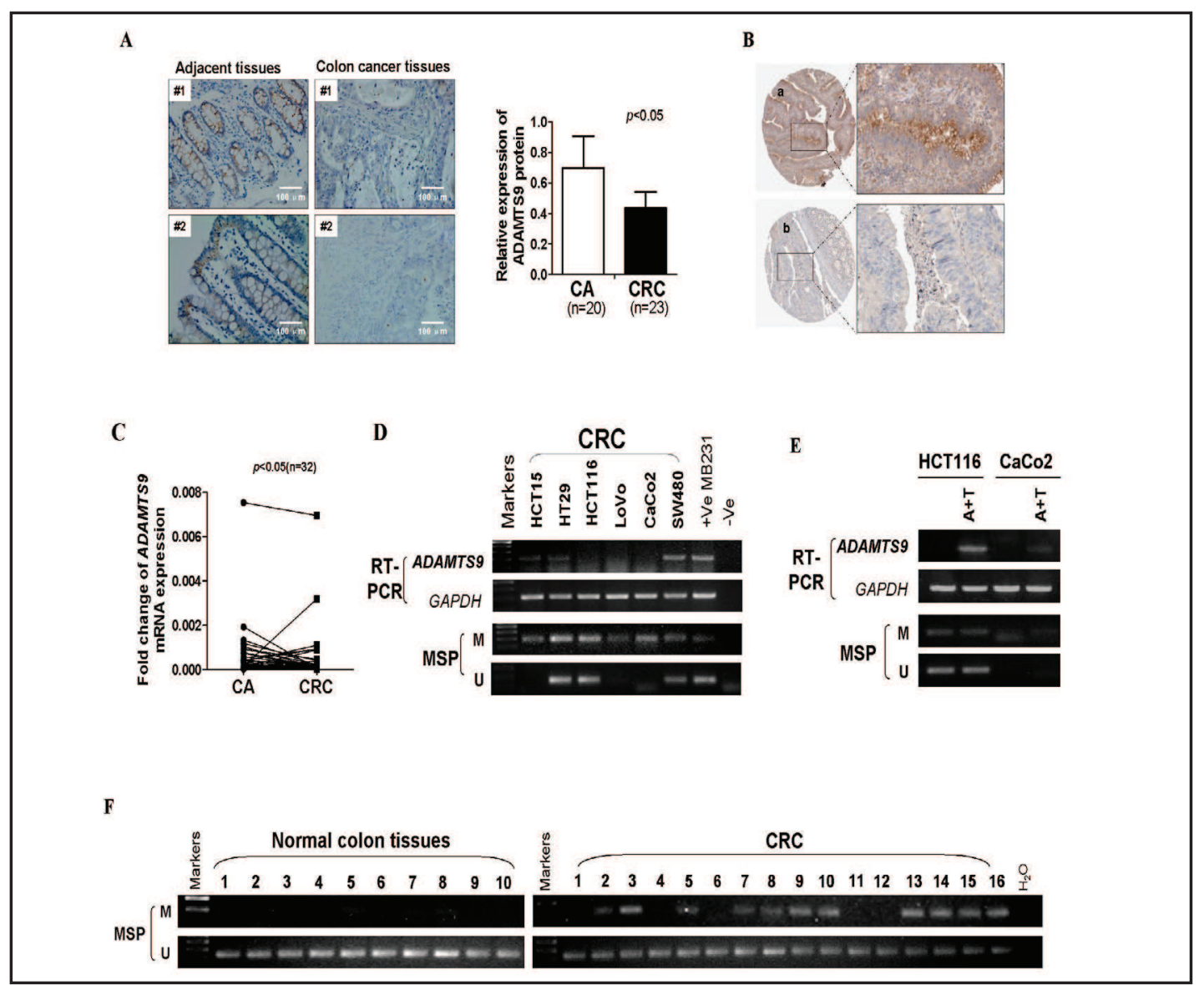

Fig. 1. Expression and methylation status of ADAMTS9 in colorectal cancer. (A).Left:Immunohistochemical staining of ADAMTS9 in human colon carcinoma tissues and cancer adjacent normal tissues. right: Quantitative analysis of mean optical density (MOD) of ADAMTS9 expression in two groups was shown as values of mean $\pm S D(p<0.05)$. (B) ADAMTS9 protein show cytoplasmic and membranous localization. Data is from the human protein atlas (http://www.proteinatlas.org/).a:colon normal tissue, b:colon adenocarcinoma. (C) ADAMTS9 expression level in paired colorectal cancer tissues by quantitative real-time PCR. (D) ADAMTS9 expression and methylation status of the ADAMTS9 promoter by MSP in a panel of human colorectal cancer cell lines by semi-quantitative PCR, GAPDH was used as control. +Ve MB231: breast cancer cell line MB231 was used as positive control. -Ve: negative control. M: methylated; U: unmethylated. (E) Pharmacological demethylation restored expression of ADAMTS9. HCT116 and CaCo2 were treated with Aza combined with TSA (A+T). ADAMTS9 expression level examined by semi-quantitative PCR and methylation status of the ADAMTS9 promoter by MSP in HCT116 and CaCo2 cell lines after A+T treatment. GAPDH was used as control. (F) left: Mehtylation status of ADAMTS9 in normal colon tissues. right: Mehtylation status of ADAMTS9 in colorectal cancer tissues.

We also investigated the level of ADAMTS9 promoter methylation in colorectal cancer tissues. MSP results showed that ADAMTS9 was methylated in $68.75 \%$ (44/64) of primary colorectal cancer tissues, but no methylation was found in normal colorectal tissues (Fig. $1 \mathrm{~F})$.

ADAMTS9 inhibits cell growth in CRC cells

The frequent silencing of ADAMTS9 in CRC cells and tissue specimens suggested that this gene might be a tumor suppressor. Colony formation assay and CCK8 assays were used to investigate whether ADAMTS9 can inhibit tumor cell growth. Exogenous expression of ADAMTS9 reduced colony formation in $\mathrm{CaCo} 2$ and HCT116 cells, relative to cells transfected 


\section{Cellular Physiology \\ Cell Physiol Biochem 2017;44:1370-1380 \\ \begin{tabular}{l|l}
\hline DOI: $10.1159 / 000485534$ & (c) 2017 The Author(s). Published by S. Karger AG, Base
\end{tabular} and Biochemistry Publisnea on online: November 30, 2017 www.karger.com/cpb

Fig. 2. ADAMTS9

inhibited cell proliferation in colorectal cancer cell lines. (A) The ectopic expression of ADAMTS9 in CaCo2 and HCT116 and knockdown of ADAMTS9 in SW480 were verified by RT-PCR. (B) The ectopic expression of ADAMTS9 in $\mathrm{CaCo} 2$ and HCT116 were verified by WesternBlot. (C) Representative colony formation assay of ADAMTS9-expressing CaCo2 and HCT116 cell lines. (D) MTS assay for cellular proliferation of $\mathrm{AD}$ AMTS9 overexpression and knockdown tumor cell lines. ${ }^{* * *} p$ $<0.001,{ }^{* *} p<0.01,{ }^{*} p$ $<0.05$.
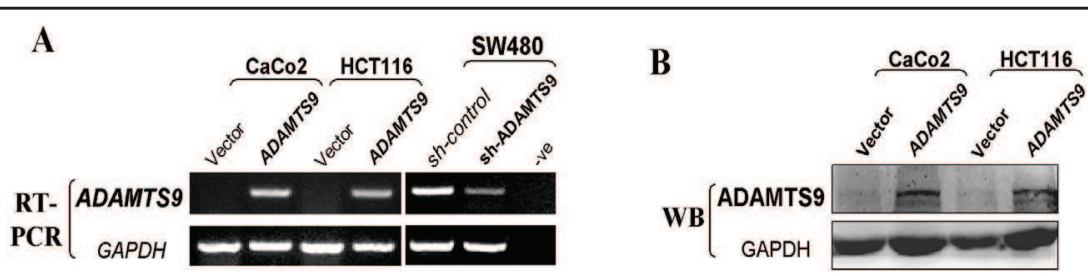

C
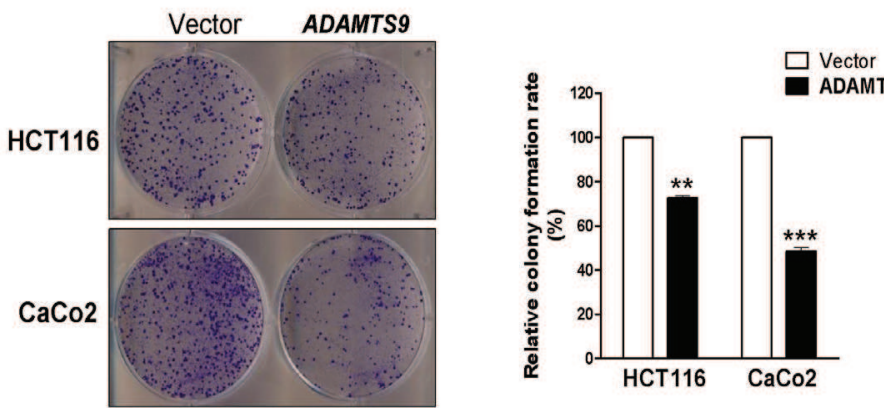

D

HCT116

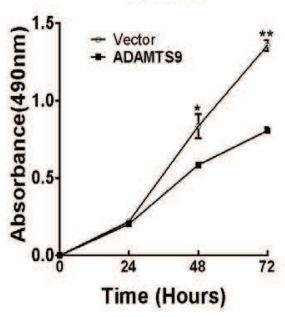

$\mathrm{CaCO} 2$

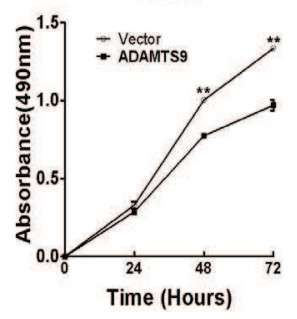

SW480

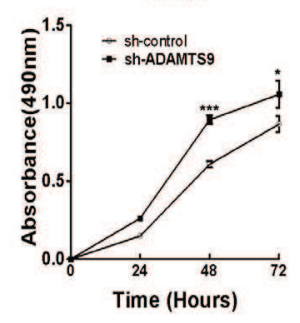

with the empty vector (Fig. 2C). In CaCo2 and HCT116 cells overexpressing ADAMTS9, cell proliferation was significantly suppressed (Fig. 2D). In addition, knockdown of ADAMTS9 in SW480 by shRNA significantly promoted cell growth (Fig. 2D).

ADAMTS9 induces G0/G1 cell cycle arrest and apoptosis in colorectal cancer cells

We sought to confirm whether ADAMTS9 regulated cell cycle and apoptosis in CRC cells. Compared to control cells, cells transfected with ADAMTS9 were arrested in the G0/ G1 phase, accompanied by the decrease of cells in G2/M and S phase (Fig. 3A). Suppression of cell growth in tumors is usually associated with the activation of cell death pathways. The percentage of early and late apoptotic cells increased in cells transfected with ADAMTS9, relative to control cells (Fig. 3B). The expression of down-stream target genes of the p53 signaling pathway, such as caspase 3, caspase 9, PARP, p21, p27 increased in CRC cell lines transfected with ADAMTS9 (Fig. 3C, 3D).

ADAMTS9 suppresses epithelial-mesenchymal transition (EMT) and migration of CRC cells

Transwell assay was performed using CaCo2 and HCT116 cells to assess the effect of ADAMTS9 on colon cancer migration.The number of cells adhering to the lower membrane of the transwells was lower in cells overexpressing ADAMTS9 than in control cells $(p<0.001$, Fig. 4A, 4B). qPCR and western blot analysis showed that the expression of the epithelial marker E-cadherin was up-regulated in cells overexpressing ADAMTS9, while vimentin was repressed, providing more evidence that ADAMTS9 represses EMT (Fig. 4C, 4D). 

Cellular Physiology Cell Physiol Biochem 2017;44:1370-1380 \begin{tabular}{|l|l|l|l|l}
\hline DOI: 10.1159/000485534 & 02017 The Author(s). Published by S. Karger AG, Basel \\
\hline
\end{tabular} and Biochemistry Publisned online: November 30, 2017 www.karger.com/cpb

A
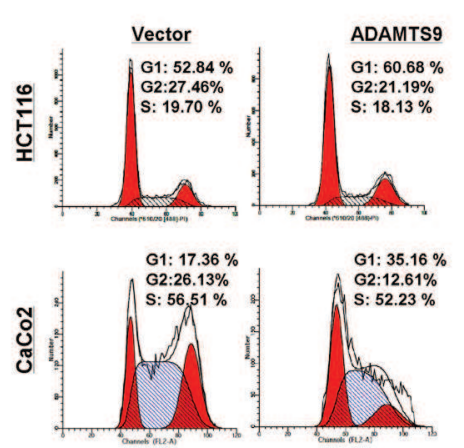

B
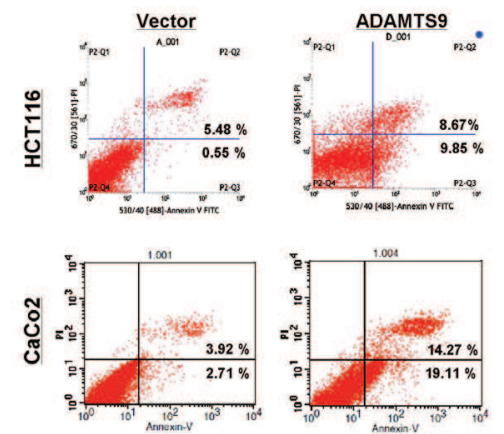
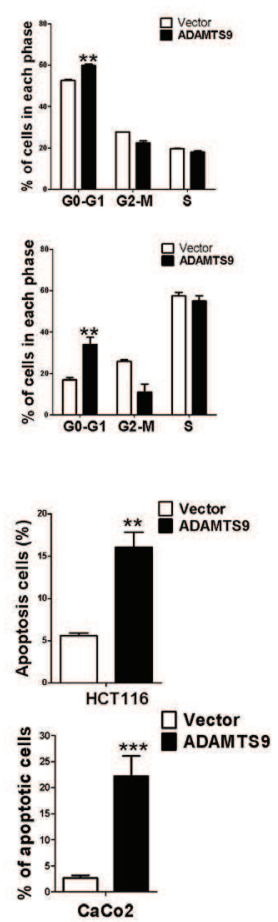

C
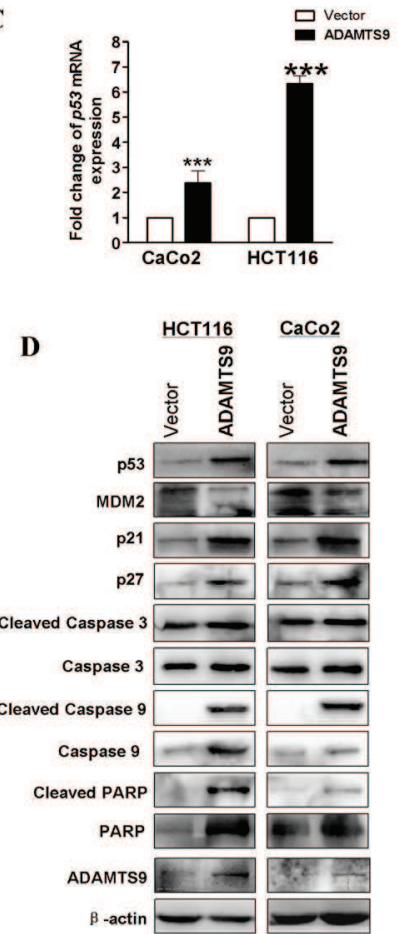

Fig. 3. ADAMTS9 induces G0/G1 cell cycle arrest and apoptosis of colorectal cancer cells. (A) Left: Representative distribution of cell cycles in $\mathrm{CaCo} 2$ and HCT116 cell lines. Right: Summary of flow cytometry data. Values are expressed as means \pm SD from three experiments and the asterisks indicate statistical significance compared to controls. ${ }^{* *} p<0.01$. (B) Left: Relative cell apoptosis rate was detected by flow cytometric analysis with Annexin V-FITC and PI double staining. Right: Summary of flow cytometry data. Values are expressed as means \pm SD from three experiments and the asterisks indicate statistical significance compared to controls. ${ }^{* *} p<0.001 .{ }^{* *} p<0.01$. (C) p53 level was evaluated in ADAMTS9 ectopic expressed colorectal cancer cell lines $\mathrm{CaCo} 2$ and HCT116 by quantitative real-time PCR. (D) Apoptosis related proteins were evaluated in vector- and ADAMTS9-infected cells by western blot. $\beta$-actin was used as an internal control.

\section{ADAMTS9 regulates Akt/VEGFA signaling in CRC cells}

The Akt/VEGFA signaling pathway contributes to proliferation and metastasis in colorectal cancer. To gain insight into the possible mechanism of ADAMTS9 in colorectal cancer, we tested the expression levels of key molecules in the Akt/VEGFA signaling pathway by western blot. Total Akt, p-Akt, and VEGFA were down-regulated in CRC cell lines transfected with ADAMTS9 (Fig. 5).

\section{Discussion}

ADAMTS family plays functions roles in extracellular matrix (ECM) assembly and degradation. By acting on a large panel of extracellular substrates, an increasing body of evidence indicates that several members of ADAMTS family shows anti-tumorigenic properties through regulated cell adhesion, proliferation, and migration [25]. Most of ADAMTS family members (ADAMTS1, ADAMTS8, ADAMTS9, ADAMTS12, ADAMTS15 and

ADAMTS18) share a complex structural design characterized by the presence of a metalloproteinase domain linked to a variety of specialized ancillary domains, including a series of thrombospondin type 1 (TSP1) repeats [26-28]. 


\section{Cellular Physiology Cell Physiol Biochem 2017:44:1370-1380

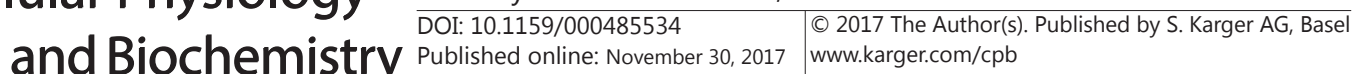

Fig. 4. ADAMTS9 suppresstransition (EMT) and migration of CRC cells. (A) Representative images of transwell migration assays. The pictures were taken 48 $\mathrm{h}$ after seeding (magnification $\times 200$ ). (B) The number of cells was counted in five representative high power fields per transwell, ${ }^{* * *} p$ $<0.001$. (C) Relative mRNA expression level by qRT-PCR of E-cadherin and vimentin in HCT116 and CaCo2 cells stably overexpressing ADAMTS9 or control vector. Expression levels were normalized to GAPDH expression. ${ }^{* * *} p<0.001$. (D) WesternBlot result of EMT associated protein E-cadherin and vimentin in vector- and $\mathrm{AD}$ AMTS9-overexpressing cells; $\beta$-actin was used as a loading control. es epithelial-mesenchymal

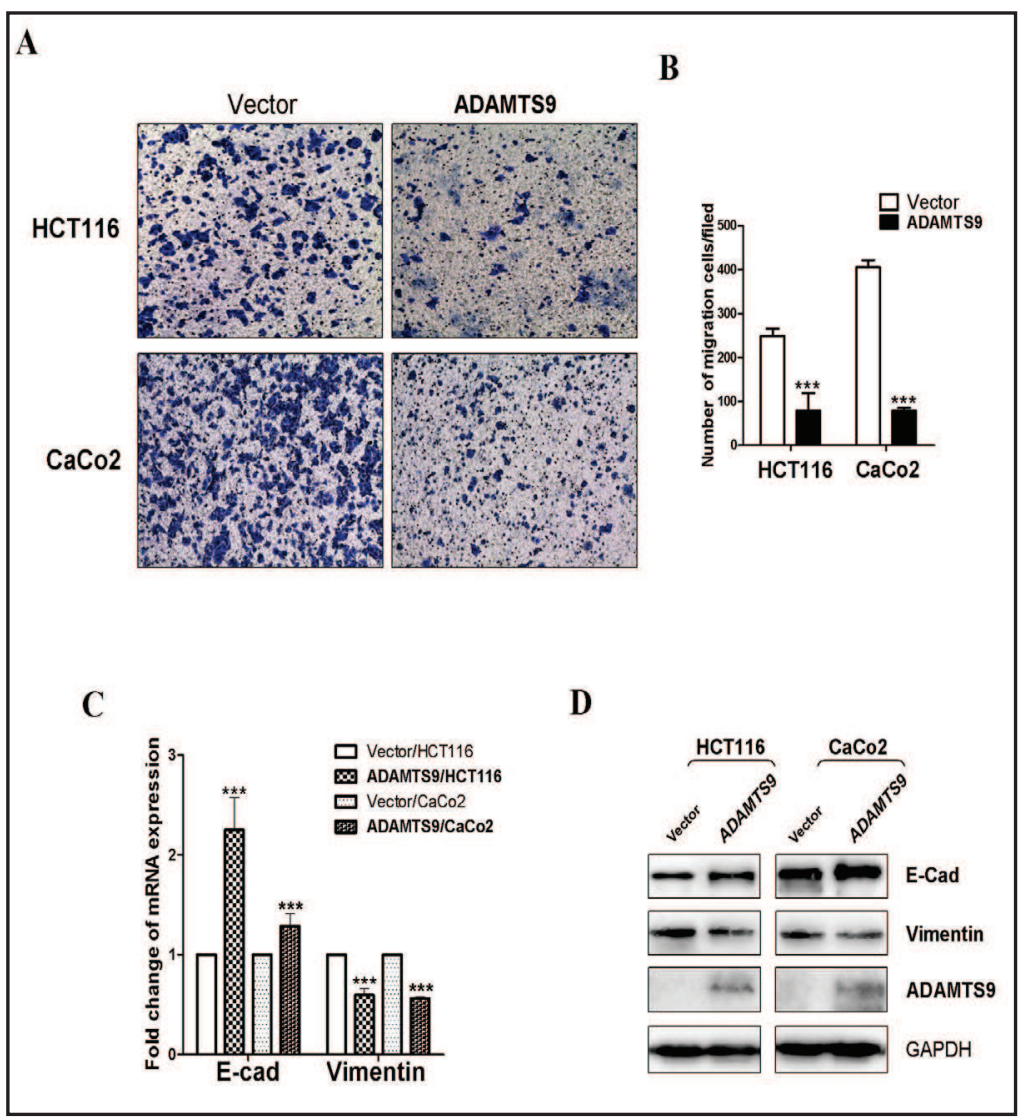

Previous studies reported that ADAMTS genes (e.g. ADAMTS8, ADAMTS12 and ADAMTS18) were frequently methylated and down-regulated in various carcinomas [2931]. ADAMTS1, ADAMTS15 and ADAMTS20 are down-regulated in CRC progress [32-33]. It has also been shown that the promoters of ADAMTS1, ADAMTS5, ADAMTS9, ADAMTS12, ASDAMTS15 and ADAMTS18 are methylated in CRC, suggesting a decreased expression of the proteins in this state [29-31, 34]. In contrast, ADAMTS4, and ADAMTS5 are overexpressed in CRC, which might be an invasive mechanism of cancer cells to degrade proteoglycans of ECM [32]. Other studies found that ADAMTS15 and ADAMTS18 were frequently mutated in CRC cells, but the functions were not clear. Hence, it is of potential clinical value to investigate the expression and methylation of ADAMTS genes in CRC.

ADAMTS9 is an extracellular matrix metalloprotease with proteolytic activity, localizes to the cell surface and in the ECM [35].

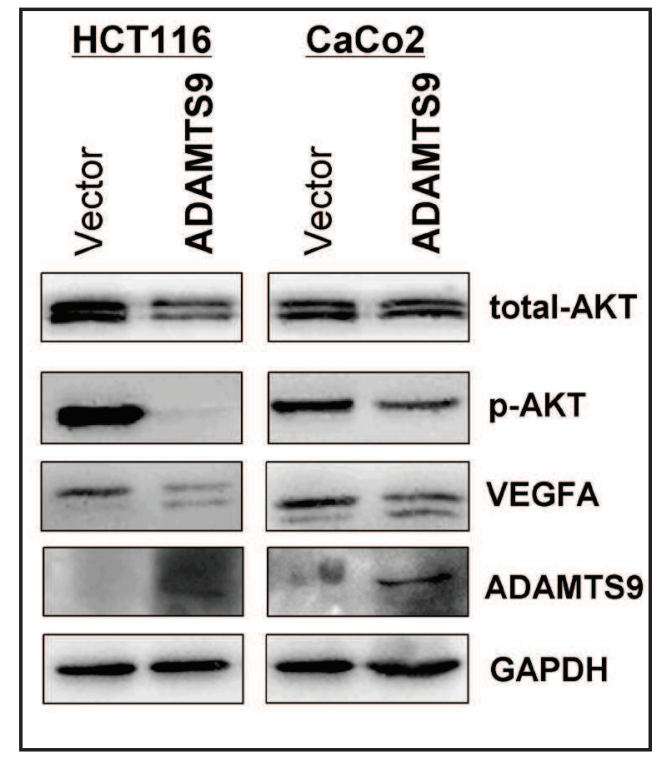

Fig. 5. ADAMTS9 regulates Akt/VEGFA signaling in CRC cells. Western-Blot was performed using antibodies against total-Akt, p-Akt, VEGFA; GAPDH was used as a control.

ADAMTS9 is silenced or down-regulated in esophageal squamous cell carcinoma, nasopharyngeal carcinoma, and gastric cancer [14-16, 36]. The down-regulation of ADAMTS9 in multiple carcinomas is due to hypermethylation of 


\section{Cellular Physiology Cell Physiol Biochem 2017;44:1370-1380 \begin{tabular}{ll|l} 
and Biochemistry & Published online: November 30, 2017 & $\begin{array}{l}\text { @ } 2017 \text { The Author(s). Published by S. Karger AG, Basel } \\
\text { www.karger.com/cpb }\end{array}$ \\
\hline
\end{tabular} \\ Chen et al.: ADAMTS9 As Tumor Suppressor in Colorectal Cancer}

promoter CpG islands [37-38]. Furthermore, ADAMTS9 reduces phosphorylation of mTOR downstream targets, including p70 ribosomal S6 kinase, eIF4E-binding protein, and downregulated hypoxia-inducible factor- $1 \alpha[15]$.

In this study, we observed that ADAMTS9 was silenced or down-regulated in five colorectal cancer cell lines and repressed in $65.6 \%$ of colorectal cancer tissues, indicating that a loss of ADAMTS9 expression could lead to colorectal cancer tumorigenesis.

MSP revealed that ADAMTS9 promoter methylation was partially responsible for its down-regulation in CRC. Furthermore, down-regulation of ADAMTS9 correlated with promoter methylation in most cell lines. The methylation of ADAMTS9 in SW480 cells showed a limited effect on mRNA expression. This might be caused by the heterogeneity of tumor cells. Aza inhibited promoter methylation and restored the expression of ADAMTS9, suggesting that promoter methylation is a predominant regulatory mechanism of ADAMTS9 inactivation in colorectal cancer.

ADAMTS9 was silenced or down-regulated in colorectal cancer cell lines and human CRC tissue specimens, suggesting that ADAMTS9 might be a potential TSG, and that its inactivation could have a role in the development of colorectal cancer. Our results indicate that exogenous ADAMTS 9 expression in $\mathrm{CaCo} 2$ and HCT116 cells induce apoptosis, suppress cell growth and cell migration, and induce G0/G1 cell cycle arrest. On the other hand, knockdown of ADAMTS9 in SW480 cells significantly promoted cell proliferation.

ADAMTS9 could also reverse EMT. In addition, the mesenchymal marker vimentin was inhibited and E-cadherin was up-regulated by ADAMTS9.Akt pathway plays an important role in cancer development and progression by regulating cell proliferation and apoptosis [39-40]. We analyzed the relationship between ADAMTS9 and Akt signaling pathway in colorectal cancer. ADAMTS9 inhibited the expression of p-Akt and VEGFA, but up-regulated the expression of p53 in CRC. Whereas p53, another downstream target gene of Akt, is very important tumor suppressor gene in multiple carcinogenosis, these results imply that ADAMTS9 might act as a tumor suppressor in colorectal cancer.

\section{Conclusion}

In summary, our results demonstrated that ADAMTS9 expression is frequently silenced by promoter methylation in colorectal cancer cell lines and primary CRC tissues. Expression of ADAMTS9 was restored by pharmacological demethylation. Down-regulation of ADAMTS9 in colorectal cancer increased cell proliferation. ADAMTS9 functions as a tumor suppressor, acting on the Akt/p53 signaling pathway in colorectal carcinogenesis.

\section{Disclosure Statement}

The authors declare that they have nothing to disclose.

\section{Acknowledgements}

The authors thank Prof. Qian Tao (the Chinese University of Hong Kong, Hong Kong, China) for generously providing cell lines, plasmids, primers, technical assistance and help with experimental design.

This study was supported by the National Natural Science Foundation of China (No 81572769), the Natural Science Foundation of Chongqing (cstc2016 jcyjA0309) and special research funds from the Chinese University of Hong Kong. 


\section{Cellular Physiology Cell Physiol Biochem 2017;44:1370-1380 \begin{tabular}{ll|l} 
DOI: 10.1159/000485534 & () 2017 The Author(s). Published by S. Karger AG, Basel
\end{tabular} and Biochemistry Published online: November 30, 2017 www.karger.com/cpb}

Chen et al.: ADAMTS9 As Tumor Suppressor in Colorectal Cancer

\section{References}

1 Torre LA, Bray F, Siegel RL, Ferlay J, Lortet-Tieulent J, Jemal A: Global cancer statistics, 2012 CA Cancer J Clin 2015;65:87-108.

2 Meining A, Morgner A, Miehlke S, Bayerdorffer E, Stolte M: Atrophy-metaplasia-dysplasia-carcinoma sequence in the stomach: a reality or merely an hypothesis? Best Pract Res Clin Gastroenterol 2001;15:983-998.

3 Fearon ER, Vogelstein B: A genetic model for colorectal tumorigenesis. Cell 1990;61:759-767.

4 Sugai T, Habano W: [Pathological Diagnosis and Its Molecular Basis in Colorectal Cancer]. Gan to kagaku ryoho Cancer Chemother 2016;43:294-299.

5 Arnold CN, Goel A, Blum HE, Boland CR: Molecular pathogenesis of colorectal cancer: implications for molecular diagnosis. Cancer 2005;104:2035-2047.

-6 Palii SS, Robertson KD: Epigenetic control of tumor suppression. Crit Rev Eukaryot Gene Expr 2007;17:295-316.

7 Wang C, Yue Y, Shao B, Qiu Z, Mu J, Tang J, Han X, Xiang T, Ren G: Dickkopf-Related Protein 2 is Epigenetically Inactivated and Suppresses Colorectal Cancer Growth and Tumor Metastasis by Antagonizing Wnt/beta-Catenin Signaling. Cell Physiol Biochem 2017;41:1709-1724.

8 Zhou X, Xie S, Yuan C, Jiang L, Huang X, Li L, Chen Y, Luo L, Zhang J, Wang D, Liu L, Shi W, Han L, Tang N, Ji Y: Lower Expression of SPRY4 Predicts a Poor Prognosis and Regulates Cell Proliferation in Colorectal Cancer. Cell Physiol Biochem 2016;40:1433-1442.

-9 Kumar S, Rao N, Ge R: Emerging Roles of ADAMTSs in Angiogenesis and Cancer. Cancers (Basel) 2012;4:1252-1299.

10 Sun Y, Huang J, Yang Z: The roles of ADAMTS in angiogenesis and cancer. Tumour Biol 2015;36:4039-4051.

11 Clark ME, Kelner GS, Turbeville LA, Boyer A, Arden KC, Maki RA: ADAMTS9, a novel member of the ADAMTS/ metallospondin gene family. Genomics 2000;67:343-350.

-12 Lando M, Fjeldbo CS, Wilting SM, B CS, Aarnes EK, Forsberg MF, Kristensen GB, Steenbergen RD, Lyng H: Interplay between promoter methylation and chromosomal loss in gene silencing at 3p11-p14 in cervical cancer. Epigenetics 2015;10:970-980.

13 Sheu JJ, Lee CH, Ko JY, Tsao GS, Wu CC, Fang CY, Tsai FJ, Hua CH, Chen CL, Chen JY: Chromosome 3p12.3-p14.2 and 3q26.2-q26.32 are genomic markers for prognosis of advanced nasopharyngeal carcinoma. Cancer Epidemiol Biomarkers Prev 2009;18:2709-2716.

14 Du W, Wang S, Zhou Q Li X, Chu J, Chang Z, Tao Q, Ng EK, Fang J, Sung JJ, Yu J: ADAMTS9 is a functional tumor suppressor through inhibiting AKT/mTOR pathway and associated with poor survival in gastric cancer. Oncogene 2013;32:3319-3328.

15 Lo PH, Lung HL, Cheung AK, Apte SS, Chan KW, Kwong FM, Ko JM, Cheng Y, Law S, Srivastava G, Zabarovsky ER, Tsao SW, Tang JC, Stanbridge EJ, Lung ML: Extracellular protease ADAMTS9 suppresses esophageal and nasopharyngeal carcinoma tumor formation by inhibiting angiogenesis. Cancer Res 2010;70:5567-5576.

16 Lo PH, Leung AC, Kwok CY, Cheung WS, Ko JM, Yang LC, Law S, Wang LD, Li J, Stanbridge EJ, Srivastava G, Tang JC, Tsao SW, Lung ML: Identification of a tumor suppressive critical region mapping to 3p14.2 in esophageal squamous cell carcinoma and studies of a candidate tumor suppressor gene, ADAMTS9 Oncogene 2007;26:148-157.

17 Peng L, Yang Z, Tan C, Ren G, Chen J: Epigenetic inactivation of ADAMTS9 via promoter methylation in multiple myeloma. Mol Med Rep 2013;7:1055-1061.

18 Mu H, Wang N, Zhao L, Li S, Li Q Chen L, Luo X, Qiu Z, Li L, Ren G, Xu Y, Zhou X, Xiang T: Methylation of PLCD1 and adenovirus-mediated PLCD1 overexpression elicits a gene therapy effect on human breast cancer. Exper Cell Res 2015;332:179-189.

19 Yin X, Xiang T, Li L, Su X, Shu X, Luo X, Huang J, Yuan Y, Peng W, Oberst M, Kelly K, Ren G, Tao Q: DACT1, an antagonist to Wnt/beta-catenin signaling, suppresses tumor cell growth and is frequently silenced in breast cancer. Breast Cancer Res 2013;15:R23.

-20 Tao Q Huang H, Geiman TM, Lim CY, Fu L, Qiu GH, Robertson KD: Defective de novo methylation of viral and cellular DNA sequences in ICF syndrome cells. Hum Mol Genet 2002;11:2091-2102.

21 Tao Q Swinnen LJ, Yang J, Srivastava G, Robertson KD, Ambinder RF: Methylation status of the Epstein-Barr virus major latent promoter $\mathrm{C}$ in iatrogenic B cell lymphoproliferative disease. Application of PCR-based analysis. Am J Pathol 1999;155:619-625. 


\section{Cellular Physiology Cell Physiol Biochem 2017;44:1370-1380 \begin{tabular}{c|l|l} 
DOI: 10.1159/000485534 & $\begin{array}{l}\text { () } 2017 \text { The Author(s). Published by S. Karger AG, Basel } \\
\text { www.karger.com/cpb }\end{array}$
\end{tabular}}

Chen et al.: ADAMTS9 As Tumor Suppressor in Colorectal Cancer

22 Li C, Tang L, Zhao L, Li L, Xiao Q Luo X, Peng W, Ren G, Tao Q Xiang T: OPCML is frequently methylated in human colorectal cancer and its restored expression reverses EMT via downregulation of smad signaling. Am J Cancer Res 2015;5:1635-1648.

23 Xiao Y, Xiang T, Luo X, Li C, Li Q, Peng W, Li L, Li S, Wang Z, Tang L, Ren G, Tao Q: Zinc-finger protein 545 inhibits cell proliferation as a tumor suppressor through inducing apoptosis and is disrupted by promoter methylation in breast cancer. PloS one 2014;9:e110990.

24 Oda T, Hayano T, Miyaso H, Takahashi N, Yamashita T: Hsp90 regulates the Fanconi anemia DNA damage response pathway. Blood 2007;109:5016-5026.

25 Lopez-Otin C, Matrisian LM: Emerging roles of proteases in tumour suppression. Nat Rev Cancer 2007;7:800-808.

26 Apte SS: A disintegrin-like and metalloprotease (reprolysin type) with thrombospondin type 1 motifs: the ADAMTS family. Int J Biochem Cell Biol 2004;36:981-985.

-27 Rocks N, Paulissen G, El Hour M, Quesada F, Crahay C, Gueders M, Foidart JM, Noel A, Cataldo D: Emerging roles of ADAM and ADAMTS metalloproteinases in cancer. Biochimie 2008;90:369-379.

28 Porter S, Clark IM, Kevorkian L, Edwards DR: The ADAMTS metalloproteinases. Biochem J 2005;386:15-27.

29 Choi GC, Li J, Wang Y, Li L, Zhong L, Ma B, Su X, Ying J, Xiang T, Rha SY, Yu J, Sung JJ, Tsao SW, Chan AT, Tao Q: The metalloprotease ADAMTS8 displays antitumor properties through antagonizing EGFR-MEK-ERK signaling and is silenced in carcinomas by CpG methylation. Mol Cancer Res 2014;12:228-238.

- 30 Moncada-Pazos A, Obaya AJ, Fraga MF, Viloria CG, Capella G, Gausachs M, Esteller M, Lopez-Otin C, Cal $\mathrm{S}$ : The ADAMTS12 metalloprotease gene is epigenetically silenced in tumor cells and transcriptionally activated in the stroma during progression of colon cancer. J Cell Sci 2009;122:2906-2913.

-31 Jin H, Wang X, Ying J, Wong AH, Li H, Lee KY, Srivastava G, Chan AT, Yeo W, Ma BB, Putti TC, Lung ML, Shen ZY, Xu LY, Langford C, Tao Q: Epigenetic identification of ADAMTS18 as a novel 16q23.1 tumor suppressor frequently silenced in esophageal, nasopharyngeal and multiple other carcinomas. Oncogene 2007;26:7490-7498.

32 Filou S, Korpetinou A, Kyriakopoulou D, Bounias D, Stavropoulos M, Ravazoula P, Papachristou DJ, Theocharis AD, Vynios DH: ADAMTS expression in colorectal cancer. PLoS One 2015;10:e0121209.

33 Viloria CG, Obaya AJ, Moncada-Pazos A, Llamazares M, Astudillo A, Capella G, Cal S, Lopez-Otin C: Genetic inactivation of ADAMTS15 metalloprotease in human colorectal cancer. Cancer Res 2009;69:4926-4934.

-34 Przemyslaw L, Boguslaw HA, Elzbieta S, Malgorzata SM: ADAM and ADAMTS family proteins and their role in the colorectal cancer etiopathogenesis. BMB Rep 2013;46:139-150.

35 Somerville RP, Longpre JM, Jungers KA, Engle JM, Ross M, Evanko S, Wight TN, Leduc R, Apte SS: Characterization of ADAMTS- 9 and ADAMTS-20 as a distinct ADAMTS subfamily related to Caenorhabditis elegans GON-1. J Biol Chem 2003;278:9503-9513.

- 36 Lung HL, Lo PH, Xie D, Apte SS, Cheung AK, Cheng Y, Law EW, Chua D, Zeng YX, Tsao SW, Stanbridge EJ, Lung ML: Characterization of a novel epigenetically-silenced, growth-suppressive gene, ADAMTS9, and its association with lymph node metastases in nasopharyngeal carcinoma. Int J Cancer 2008;123:401-408.

- 37 Zhang C, Shao Y, Zhang W, Wu Q, Yang H, Zhong Q Zhang J, Guan M, Yu B, Wan J: High-resolution melting analysis of ADAMTS9 methylation levels in gastric, colorectal, and pancreatic cancers. Cancer Genet Cytogenet 2010;196:38-44.

- 38 Peng L, Yang Z, Tan C, Ren G, Chen J: Epigenetic inactivation of ADAMTS9 via promoter methylation in multiple myeloma. Mol Med Rep 2013;7:1055-1061.

39 Luo J, Manning BD, Cantley LC: Targeting the PI3K-Akt pathway in human cancer: rationale and promise. Cancer Cell 2003;4:257-262.

40 Vivanco I, Sawyers CL: The phosphatidylinositol 3-Kinase AKT pathway in human cancer. Nature Rev Cancer 2002;2:489-501. 